\title{
On the relationship between teamwork and supporting knowledge management
}

\author{
Mahshad Erfanian khanghahi \\ Department of Management, Payamnoor University of Mazandaran, Mazandaran, Iran \\ Email address: \\ mekh509@yahoo.com \\ To cite this article: \\ Mahshad Erfanian khanghahi. On the Relationship between Teamwork and Supporting Knowledge Management. Science Journal of \\ Business and Management. Vol. 2, No. 5, 2014, pp. 123-130. doi: 10.11648/j.sjbm.20140205.12
}

\begin{abstract}
This study aims at investigating how far teamwork can support Knowledge Management. In doing so, 384 employees working in Iran Khodro, Neyshabour branch, located in Khorasan-e-Razavi, Iran were randomly selected as our participants. Based on studies done, we distinguish which features of teamwork support the KM course of action in its different phases (i.e. formation, transfer and incorporation). In order to analyze the data obtained, multiple regression and analysis of variance were used. The results of the study indicated that complementary skills (H2) and a climate of trust (H3) in teamwork were more significant factors that support management of organizational knowledge.
\end{abstract}

Keywords: Knowledge Management, Teamwork, Knowledge Formation, Transfer, Incorporation of Knowledge

\section{Introduction}

The global economy has turned an industrial manufacturing/product-oriented economy into one which is based on knowledge and services, and the principal product is information or knowledge. Successful management of intellectual capital is a significant issue challenging organizations in today's global and knowledge-driven economy [46].

Contrary to the conventional stress on external factors to elucidate organizational success [34], recent planned management literature has focused on internal resources [24]. Some scholars including $[15,30]$ assert that knowledge is the focal source of sustainable competitive advantage. If we review the specialist literature in search of models of knowledge management that can help companies to take full advantage of that resource, we will find that the activity must focus on three distinct aspects. First, it is necessary to create the resource. Knowledge, by definition, is buried in the minds of individuals $(12,14,32)$ and therefore, those people are held accountable for its formation. Next, any persons within the organization, who have created the knowledge, will have to be transferred from those individuals to others in order to be shared. Finally, those fragmented pieces of knowledge, once they are transferred and received, will have to be unified and thus become one mass of knowledge [49].

Hence, knowledge management can be conceptualized as a course of action which its material is the individual knowledge of a person, which is created, transferred and integrated in teamwork within the company, whereas its product is organizational knowledge, which, in fact, is a source of competitive advantage (see figure 1). At stage during the process, [16] states that many current potentialities in organizational design may be inferred as attempts to access and integrate the implied knowledge of members of an organization, while at the same time recognizing the obstacles to transfer that knowledge. This replicates the need for a close interdependence between specialists so as to integrate their know-how [16].

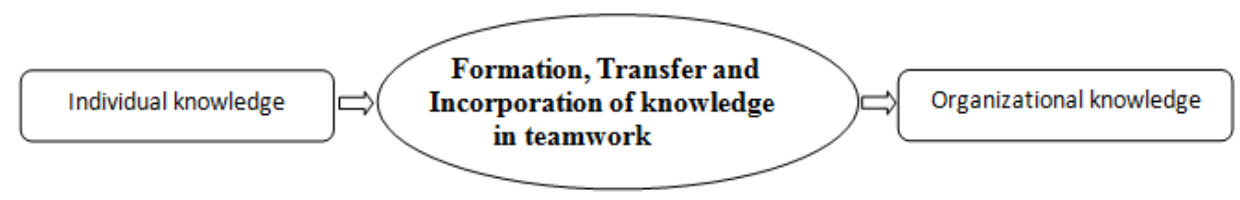




\section{Subject Arrangement}

Not only has knowledge management been perceived by organizations in recent times, but it has also made significant changes in the business market. Some of researchers emphasized on teamwork, in order for knowledge management to be supported. Management practice field displays that the past two decades have experienced a remarkable increase in the use of teamwork. From $[16,17]$ viewpoint, this new potentiality of organizational design could be regarded as a way to gain the implied knowledge of the organizational personnel and so as a way to form the proper situation for knowledge management. However, for individual knowledge to become organizational knowledge, it is not enough to organize the firm around teamwork [50].

As a result, the primary question of the research is: What is the relationship between teamwork and knowledge management?

So, our hypothesis is that the there is no relationship between teamwork and knowledge management. In this case, the primary aim is to recognize the features that teamwork needs to support knowledge management. Then, the second aim is to test empirically how those characteristics have a desired impact on knowledge management, which is regarded as a process of formation $(\mathrm{F})$, transfer $(\mathrm{T})$ and incorporation (I) of the team work personnel's knowledge. The rest of the paper is structured as it follows.

The next section develops the theoretical framework of the paper. The third section describes the methodology used to verify the hypotheses empirically. Finally, the main conclusions are discussed based on the results obtained.

\subsection{Theoretical Framework of $K M$}

The increasing speed of the changes in markets, products, technologies, competitors, and regulations and even in society means important structural variations that modify what is strategic for organizations [41]. In other words, knowledge of environment is a key strategic resource that allows organizations to gain continuing competitive merits $[14,30,38]$.

The knowledge generation process, as Cook and Brown (1999) state, includes all behaviors by which new knowledge are created within the organization. There are several ways to generate knowledge, that is to say:

Acquiring mode in which the new knowledge is acquired from external sources.

Externalizing mode through which the adaptable implied knowledge of the personnel of the organization is conceptualized, expressed, and externalized.

Discovering mode where the knowledge concealed in the data sources of the organization is discovered.

Synthesizing mode where the new knowledge is generated either by integrating the newly generated and validated knowledge via the on hand knowledge or by mixing the on hand knowledge.
Producing (formation) mode where the new knowledge is produced by interacting with the things in cognitive domains of the enterprises.

Knowledge management may be defined as doing what is needed to get the most out of knowledge resources [3]. It focuses on organizing and making available important knowledge [39], and then forming organizational knowledge $[28,29,32]$.

The main problem in doing so is that knowledge is a resource generated within the individual [32], or as [17] says, knowledge is embedded in the members of the organization in a specialized way; consequently, the challenge for knowledge management is to know how to transform individual knowledge into organizational knowledge, which amounts to something more than the sum of those personnel's individual knowledge and its owner is the organization.

Knowledge management process has been studied by many authors $(16,18,32)$ and in summarizing their ideas; we can say that individual knowledge once created has to undergo a process of transfer and incorporation that gives rise to organizational knowledge. This process will occur in different, but linked, ontological levels. Firstly, knowledge created (formation) in the mind of each individual of a small group should be transferred to others (transfer), then, that shared knowledge should be assimilated among them (incorporation), thus generating the group knowledge (which is now part of organizational knowledge). Afterwards, the knowledge born in every group will be transferred and integrated between groups in a single work place, department, and area or similarly, leading to knowledge of higher ontological level. Finally, the transfer and incorporation of knowledge created in other sections of the firm will give rise to organizational knowledge [50].

In the light of the review carried out, the function of the organization must center on supporting these creative individuals by providing them with the appropriate setting for the formation of knowledge. That is, that setting must be such that it makes the organization resemble individual initiative [49].

\subsection{Structure of a KM}

Since traditional organizations are vertically structured around tasks and functions, they are not suitable for sharing knowledge at the organization level. Analogously, other elements of hierarchal structure such as rigid adherence to organization chart hamper knowledge flow. In contrast, improving the company's core competency in the current networked economy depends on leveraging and sharing of knowledge more than managing the people themselves. Accordingly, the real power must now shift not only to those who attain the knowledge, but more importantly to those who possess the talent for leveraging knowledge.

A knowledge organization is made up of knowledge groups that are composed of knowledge teams, which are built from knowledge workers selected for contributing to a 
knowledge team due to their tacit knowledge and skills. Ideally, the knowledge workers on any knowledge team come from different organizational (and educational) backgrounds and will bring a diversity of tacit knowledge and skills to the team [37].

The recognition of individual personnel as knowledge workers will promote the development of new knowledge teams to address the organization's opportunities, and consequently will facilitate the development of knowledge team communities that are diverse and more focused on knowledge-oriented problem solving. Knowledge workers are expected to share and utilize knowledge with other team members to produce the highest quality decisions. New knowledge teams and groups must be promoted to develop around product lines or other core competencies of the enterprise as opposed to functional area team composition. Knowledge teams should be created dynamically to take advantage of the organization's business opportunities or new business strategies. Knowledge teams that identify the need for specific knowledge would then recruit knowledge workers that had the desired tacit knowledge to join the team. The role of a knowledge librarian or expertise locater system can facilitate the identification and location of knowledge workers with desired tacit knowledge and skills $(37,2005)$.

\subsection{Teamwork}

A work team is a group of interdependent individuals who solve problems or complete tasks within an organizational context, share responsibility for the results and are seen by themselves and by others as an intact social entity belonging to a larger social system, and which manages its relationship within the confines of the organization $[1,7,13]$.

Moreover, face-to-face contact and close personal relationships are the basis for a community of practice, because when the members get to know one another and they have a sense of mutual trust, they gain legitimacy in the eyes of the others [50].

\subsubsection{Characteristics of Teamwork to Support KM}

In general, the literature on knowledge management indicates which factors affect the formation, transfer and incorporation (FTI). Therefore, in this section of paper, an attempt will be made to represent one group of factors supporting knowledge management in teamwork.

According to [28], self-management is the first characteristic which requires that the team should become a social context in itself, within which personal knowledge can be expanded. Hence, in order to support knowledge management, it is essential to build self-management teams. In self-managed teams the important decisions are made and executed by the teams [19].

Self-managed teams are part of formal structure of the organization. Based on the above discussion, the following hypothesis has been proposed:

H1. The self-leaded team supports KM (FTI)

High levels of team self-sufficiency may actually decrease individual independence and responsibility is softened rather than granted to a single individual when important decision making is shared rather than carried out alone [43]. This aspect is positive for the teamwork to function as a mass of practice because it supports group cohesion [3].

But, in the knowledge management literature individual independence is regarded as an important aspect for generating organizational knowledge $[32,12]$. Therefore, the possibility of introducing unanticipated opportunities increases. What is more, according to [50], individual selfsufficiency will be a source of individual self-motivation to support knowledge management, especially to create knowledge.

Based on that, we set out our second hypothesis as following:

H2. The team supports KM (FTI) wherever personnel have individual self-sufficiency

As stated in the literature, if teamwork personnel are distinguished by participation and the exchange of ideas, balanced knowledge is also of great importance. This could create a positive synergy [21] since when individuals with heterogeneous and balanced skills join a team, everyone can make use of different structures and mental models that lead to multifaceted dialog $[23,36]$. Moreover, the interactions between individuals with different and diverse knowledge structures will increase the organizational capability for creating knowledge [26, 32]. So, heterogeneous and balanced skills are another important trait for supporting knowledge management. As a result of those arguments the following hypothesis is established:

H3. The team supports KM (FTI) where its members have diverse and balanced skills

According to [15], mutual understanding among the teamwork members will make the function of the mechanisms of knowledge incorporation possible, allowing the team to distribute the aspects, not of common knowledge, to all its members. However, bearing in mind that, for the effective co-ordination of a work team its size must be limited, it is impossible within the group to have access to the entire range of specialist knowledge necessary for the activity [16]. Consequently, the inclination is usually towards the construction of a formation based on teams where the members are changed if it becomes necessary, simultaneously assuring a certain redundancy of knowledge flowing within the organization [32]. This leads us to the condition that common language must be a reality of the organization and not just of the group. Based on what have been mentioned, the researcher proposes the following hypothesis:

H4. The team supports KM (FTI) where members have a mutual understanding

By and large, the teamwork does not need complicated organizational structures. Yet, its members need time and space to collaborate. They do not need much management but they do need leadership. Accordingly, [47] states that, in order to legitimize the community-which could be a team- as a place for sharing and creating knowledge, the figure of the team leader is necessary. The main task of the leader is to co- 
ordinate and focalize the different viewpoints found within the teamwork [22, 23]. In addition, following [10], team leader must provide not only real and virtual spaces for communication, but also guidelines for the team. The function of leaders is to serve as a model to the collaborators, and so, they should be prepared to share information openly, put themselves in the others' shoes, provide constructive feedbacks and show all those outlooks and behaviors related to encouraging knowledge management [50]. Therefore, the fifth hypothesis is defined as follows:

H5. The team where a leader exists favors the knowledge management (FTI)

The members of teamwork value contribution and devote their professional prestige in the team if there is a good atmosphere. If such an atmosphere is not felt by the members, then interpersonal co-operation, essential for the generation of true organizational knowledge, will not take place [48].

The literature on knowledge management has described this atmosphere as one of true internal collaboration among group members [25] that goes beyond mere communication and information exchange [9].

Within the knowledge management literature, trust is often discussed as an important element for successful knowledge management ventures [4, 36, 37].

Trust has been discussed extensively with respect to knowledge generation. However, it has been suggested that trust is required for it to thrive. The trust discussed with respect to knowledge generation is organizational trust. Knowledge generation not only occurs within individuals, but it also happens inside groups or teams. Knowledge generation inside a group often requires individuals to share their knowledge and information (which involves the second knowledge process of knowledge transfer) in order for a new knowledge to be created. The most commonly discussed knowledge management process with respect to trust is knowledge transfer (i.e. knowledge sharing). It is frequently commented that in order for people to be willing to share their knowledge, they must have trust each other [6, 20,33].

It has even been commented, "Trust is, after all, the single most important precondition for knowledge exchange" [37].

More specifically, trust has been discussed as prerequisite for tacit knowledge sharing [35, 37]. While it has not been extensively discussed, knowledge generation within a group or team setting is presumed to require trust. However, the more the organizational policies and regulations support knowledge generation for the group, then trust's importance decreases to the extent that controls and policies replace trust. On the other hand, if distrust is present, then knowledge generation will be blocked, as fear, skepticism; wariness will prevent an individual from sharing required knowledge or information with the team to generate new knowledge [11]. [44] makes recommendations for creating trust for knowledge management. The recommendations are the followings:

- $\quad$ Create a sense of mutual dependence.

- Make trustworthy behavior part of the performance evaluation.
- $\quad$ Increase individual reliability by creating a map of expectations.

- $\quad$ Share personal information in smaller groups.

- $\quad$ Use symbolic gestures for interdependency [44].

It amounts to the "mental" element of what [29] call a "'shared organizational context". [45] calls it "high care" and states that high care will be present in the team as long as the following premises exist: mutual trust, active empathy, lenience in judgment, courage and access to help. In the light of these considerations, we can establish that a climate of trust is important to knowledge management:

H6. The team supports KM (FTI) with an atmosphere of trust

\section{Research Methodology}

A field experiment was used to test our research hypotheses. In order to empirically check the proposed model of factors supporting the knowledge management (i.e. formation, transfer, and incorporation) in teamwork, questionnaires were used.

\subsection{Participants}

384 employees (62\% male and 38\% female), who has had at least 5 years of experience, participated for four months, from August to December, 2013. Employees work in Iran Khodro, Neyshabour branch, located in Khorasan-e-Razavi, Iran. The participants have been working in permanent teams at least for the last three years. The participants were selected through stratified random sampling.

\subsection{Procedure and Instrumentation}

The survey was administrated offsite by researchers. A questionnaire was sent to each member in the sample. The researchers returned at the end of daily shift to collect the completed questionnaires from the team members. If questionnaires were not completed at that time, the researchers returned the next day. This process continued for a 14-day period, until all team members had been reached and given several opportunities to complete the questionnaires. At last, there were 384 questionnaires sent to the members of the proposed sample, and 320 of them were collected for analysis.

Sixty two percent of the respondents were male. Sixty five percent had completed high school, while an appreciable thirty seven percent had university graduate degrees and the rest had elementary education. Forty two percent of respondents were in specialist ranks, thirty percent in executive ranks and twenty eight percent in managerial ranks.

Information was gathered on a number of demographic variables, work experience, and the experience of working in teams. To measure the respondents' perception about the characteristics of a work team to supporting knowledge management, thirty four items were used. The questionnaire was split into two parts. The first section had twenty items about the features of teamwork (i.e. self-management, 
individual autonomy, heterogeneous and complementary skills, mutual understanding, leadership, atmosphere of trust) to support the formation of knowledge and, the second had fourteen items about the characteristics of work teams (i.e. self-management, individual self-sufficiency, diverse and balanced skills, mutual understanding, leadership, atmosphere of trust) to support transfer and incorporation of knowledge. Those items (34 items) that the literature considers to support knowledge management were used.

The questionnaire was of a five-point Likert scale type and the respondents indicated the extent from very little to very much with 34 statements $(1=$ strongly disagree, $5=$ strongly agree).
In order to test the validity factor of scale, first, a standard questionnaire was customized based on conceptual framework and field study was used by [50] and then, some of experts and senior specialists of Iran Khodro Company and academic people confirm validity of scale (face validity). In addition, to test the factor reliability of scale, several Cronbach's $\alpha$ analyses were conducted. Reliability analyses were carried out for the joint scale and for each of its dimensions, and $\alpha$-values ranging from 0.6 to 0.8 indicate that we obtained acceptable measuring instruments (The results of Cronbach's $\alpha$ analyses for each of the dimensions are shown in table 1).

Table 1. Analysis of reliability of the scales used to measure the factors supporting KM (CTI) in teamwork

\begin{tabular}{lll}
\hline Factor & Cronbach's alpha of formation & Cronbach's alpha of transfer and incorporation \\
\hline Self-management & 0.752 & 0.782 \\
Individual autonomy & 0.633 & 0.852 \\
Mutual understanding & 0.757 & 0.846 \\
Member's heterogeneous and complementary skills & 0.740 & 0.815 \\
Leadership & 0.826 & 0.844 \\
Atmosphere of trust & 0.732 & 0.799 \\
\hline
\end{tabular}

\subsection{Data Analysis}

In this study, the inferential method of data analysis, namely, multiple regression and analysis of variance (ANOVA) were conducted. To enter variables in the model, forward method was used. Then, the data was analyzed through software of SPSS version 15. In order to test the hypotheses, the data were analyzed in two stages. In the first stage, regression analyses were conducted to evaluate the relative importance of each features of teamwork to the degree of knowledge formation in the team. In the second stage, the same process to the degree of transfer and incorporation of knowledge in teamwork was conducted. Finally, a new variable from combining both the factors of $\mathrm{C}$ and TI was created to obtain a combined measure of knowledge management (FTI) in work team. That variable was calculated from weighted average of the two extracted factors of $\mathrm{F}$ and $\mathrm{TI}$.

\section{Result}

To test the relative importance of qualities of the teamwork among personnel to support knowledge management, three multiple regression analyses were done, all of which indicated that the six characteristics (i.e. self-management, individual self-sufficiency, diverse and balanced skills, mutual understanding, leadership, atmosphere of trust) were entered as predictor variable. Still, the criteria variable were changed: in the first analysis, the way for the formation of knowledge in the team, in the second, the degree of transfer and incorporation of knowledge, and in the third, the degree of knowledge management (FTI) among team members. The results obtained from these analyses are shown in table 2 .

Table 2. Multiple Regression Analysis

\begin{tabular}{|c|c|c|c|c|c|c|c|c|c|}
\hline \multirow{2}{*}{ factor } & \multicolumn{3}{|c|}{ Creation } & \multicolumn{3}{|c|}{ Transfer and Incorporation } & \multicolumn{3}{|c|}{ KM (CTI) } \\
\hline & B & $\mathbf{t}$ & sig & B & $\mathbf{t}$ & sig & B & t & sig \\
\hline Self-management (f1) & 0.839 & 31.302 & 0 & -0.038 & -4.168 & 0 & -0.443 & -8.603 & 0 \\
\hline $\begin{array}{l}\text { Member's heterogeneous } \\
\text { and complementary skills (f2) }\end{array}$ & -0.209 & -7.682 & 0 & 0.693 & 60.733 & 0 & 0.894 & 16.398 & 0 \\
\hline Atmosphere of trust (f3) & 0.226 & 7.123 & 0 & 0.619 & 60.36 & 0 & 0.704 & 11.919 & 0 \\
\hline Leadership (f4) & -0.495 & -18.484 & 0 & -0.185 & -23.59 & 0 & -0.317 & -7.219 & 0 \\
\hline Individual self-sufficiency (f5) & 0.337 & 13.025 & 0 & -0.48 & -44.49 & 0 & -0.254 & -4.711 & 0 \\
\hline Mutual understanding (f6) & 0.095 & 3.567 & 0 & 0.071 & 7.685 & 0 & - & - & - \\
\hline
\end{tabular}

Then, to assess level of significance of the regression model, analysis of variance (ANOVA) was conducted. The results of this analysis indicated that the model is significant (table 3). Also, the results of analysis stated that the model's
$\mathrm{R}$ square is 0.780 (table 4 ). So, the 78 percent of changes related to criterion variable were explained by predictive variables. 
Table 3. ANOVA

\begin{tabular}{|c|c|c|c|c|c|}
\hline Model & Sum of Squares & df & Mean Square & $\mathbf{F}$ & Sig. \\
\hline 1 Regression & 165.060 & 1 & 165.060 & 353.192 & $0.000^{\mathrm{a}}$ \\
\hline Residual & 143.940 & 308 & 0.467 & & \\
\hline Total & 309.000 & 309 & & & \\
\hline 2 Regression & 195.651 & 2 & 97.825 & 264.955 & $0.000^{\mathrm{b}}$ \\
\hline Residual & 113.349 & 307 & 0.369 & & \\
\hline Total & 309.000 & 309 & & & \\
\hline 3 Regression & 212.856 & 3 & 70.952 & 225.821 & $0.000^{\mathrm{c}}$ \\
\hline Residual & 96.144 & 306 & 0.314 & & \\
\hline Total & 309.000 & 309 & & & \\
\hline 4 Regression & 229.422 & 4 & 57.355 & 219.827 & $0.000^{d}$ \\
\hline Residual & 79.578 & 305 & 0.261 & & \\
\hline Total & 309.000 & 309 & & & \\
\hline 5 Regression & 241.068 & 5 & 48.214 & 215.759 & $0.000^{\mathrm{e}}$ \\
\hline Residual & 67.932 & 304 & 0.223 & & \\
\hline Total & 309.000 & 309 & & & \\
\hline
\end{tabular}

a. Predictors: (Constant), f2

b. Predictors: (Constant), f2, f5

c. Predictors: (Constant), f2, f5, $\mathrm{f3}$

d. Predictors: (Constant), f2, f5, $\mathrm{f} 3, \mathrm{fl}$

e. Predictors: (Constant), f2, f5, f3, f1, f4

f. Dependent Variable: km

It can be seen one factor is significantly related to both knowledge formation and its transfer and incorporation. That is a climate of trust. Thus, hypothesis 6 was completely supported. Although hypothesis 4 (members' diverse and balanced skills) was supported, that was only significantly related to knowledge transfer and incorporation (TI). Moreover, factors referring to self-management and individual self-sufficiency were significantly related only to knowledge formation. So, hypotheses 1 and 2 were only partially supported. The fifth hypothesis, which deals with leadership, was not totally accepted, that is, this factor (leadership) does not support the formation as well as transfer and incorporation of knowledge. Finally, H3 (common language) was not accepted, because that influence very little the forecast dependent variable, so this factor did not enter in the model.

Table 4. Model Summary

\begin{tabular}{lllll}
\hline Model & R & R Square & Adjusted R Square & Std. Error of the Estimate \\
\hline 1 & $0.731^{\text {a }}$ & 0.534 & 0.533 & 0.68362127 \\
2 & $0.796^{\text {b }}$ & 0.633 & 0.631 & 0.60763063 \\
3 & $0.830^{\mathrm{c}}$ & 0.689 & 0.686 & 0.56053145 \\
4 & $0.862^{\mathrm{d}}$ & 0.742 & 0.739 & 0.51079569 \\
5 & $0.883^{\mathrm{e}}$ & 0.780 & 0.777 & 0.47271609 \\
\hline
\end{tabular}

a. Predictors: (Constant), f2

b. Predictors: (Constant), f2, f5

c. Predictors: (Constant), f2, f5, f3

d. Predictors: (Constant), f2, f5, f3, f1

e. Predictors: (Constant), f2, f5, f3, fl, f4

f. Dependent Variable: km

It can be understood that the relative importance of each qualities of the teamwork to knowledge management varies according to which element of the process is being explained. Therefore, atmosphere of trust is the trait that best explains the degree of $\mathrm{KM}$ in the teamwork. In addition, it had an especially significant influence on both phases of the process (i.e. C and TI). However, the other factors had favorable effects of varying intensity on each of the process phases.

\section{Discussion}

In this study, we have obtained empirical confirmation that knowledge management is favored in work teams which possess certain characteristics: self-management, individual self-sufficiency, diverse and balanced skills, mutual understanding, leadership, atmosphere of trust. To implement this study, knowledge management in teamwork was conceptualized as a process of formation $(\mathrm{F})$, transfer and incorporation (TI) of the members' knowledge. The results permitted not only the verification of a positive and significant relationship between the teamwork features and knowledge management in such groups, but also a detailed examination of that relationship. So, we have obtained evidence about what features of teamwork support the knowledge management process in its different phases, and thus contribute to filling a gap in the literature.

Thus the analyses revealed that the features of teamwork that most noticeably influences the whole process of the FTI of knowledge are that labeled as atmosphere of trust. Consequently the study results show that an atmosphere of 
trust enhances knowledge management in the team and so supports the formation of individual knowledge as well as its transfer and incorporation. As [48] point out, if this atmosphere does not exist in teamwork, then interpersonal co-operation, essential for the generation of true organizational knowledge, will not take place. However, other features of the teamwork are seen to support specific stages of knowledge management. To be more specific, the members' diverse and balanced skills are significantly related only to knowledge transfer and incorporation (TI). That supports the theoretical approaches that reveal the interactions between individuals with different and diverse knowledge structures will increase the organizational capability to achieve innovation beyond which any individual member can achieve [22,32].

Different structures and mental models that produce multifaceted dialog can be achieved when personnel with diverse and balanced skills join teamwork [23, 36].

Moreover, factors referring to self-management and individual self-sufficiency are significantly related only to knowledge formation. According to [28], self-management is the first quality that the team should have to become a social context in itself, within which personal knowledge can be expanded. In addition, in the knowledge management literature individual autonomy is considered an important aspect for creating organizational knowledge $(28,12,26)$.

The fifth hypothesis, which deals with leadership, is not totally accepted, that is, this factor (leadership) does not support the formation, transfer and incorporation of knowledge. As [10] point out, team leader must provide not only real and virtual spaces for communication, but also guidelines for the team. The main task of the leader is to coordinate and focalize the different viewpoints found within the work team [20,21].

Finally, the factor of common language is not accepted, because that does not influence the forecast dependent variable, so it did not enter in the model.

On the whole, in the light of empirical results of this study and review of the literature, factors determining that teamwork supports knowledge management are identified as: self-management, individual self-sufficiency, members' diverse and balanced skills, common language, leadership, and atmosphere of trust. These six factors were corroborated by the theoretical literature and some researches [40, 41].

Although, this paper provides evidence for the necessary characteristics of teamwork that support knowledge management, but more research is needed in order to study other features of teamwork that could support knowledge management process (formation, transfer and incorporation).

\section{Limitations}

The research conducted is not without its limitations, two of which worth mentioning. The major one is the limitation with its units of analysis. It was recognized that the group rather than the individual would have been a more suitable unit of analysis. However, this approach could not be adopted in this study since only the data from 60 complete teams had been gathered. That is why individual level measures have been used. Future research should employ group measures to determine more conclusively the extent to which these features affect the knowledge management (FTI) in work team.

A second limitation is the scope of research. Since, Iran Khodro is comprised of 33 of branches in 23 regions (States) of Iran and each of those has unique features and multiplicity of subcultures, so the results of this research could not be extended to the other Iran Khodro branches.

\section{References}

[1] Alderfer, C. (1977). Groups and intergroup relations. In Richard Hackman, J. \& Lloyd

[2] Armbrecht, F. M. R., Chapas, R. B., Chappelow, C. C., Farris, G. F., Friga, P. N., Hartz, C.A., et al. (2001). Knowledge management in research and development. Research Technology Management, 44(4), 28-48.

[3] Baron, J., \& Kreps, D. M. (1999). Strategic Human Resources: Framework for General Manager. New York, NY: Wiley.

[4] Bukowitz, W., \& Williams, R. (1999). The knowledge management Fieldbook. London, UK: Financial Times Prentice Hall.

[5] Cook, S., \& Brown, J. (1999). Bridging epistemologies: the generative dance between organizational knowledge and organizational learning. Organization Science, 10(4), 381-400.

[6] Davenport, T., \& Prusak, L. (1998) Working knowledge: How organizations manage what they know. Harvard Business School Press, Boston: MASS.

[7] David, F. R., Pearce, J. A \& Randolph, W. A. (1989). Linking technology and structure to enhance group performance. Journal of Applied Psychology, 74, 233-241.

[8] Despres, C. \& D. Chauvel (Eds.), Knowledge Hirizons: The present and the promise of Knowledge Management, Boston, MA: Butterworth Heinemann, pp225-236.

[9] El Sawy, O. A., Erikson, I., Carlson, S. A., \& Raven, A. (1997) Shared knowledge creation spaces around the new product development process, working paper, California: University of Southern California.

[10] Elpper, M. J., \& Sukowski, O. (2000) Managing team knowledge: core processes, tools and enabling factors. European Management Journal, 18(3), 334-341.

[11] Ford, D. (2001). Trust and knowledge management: The seeds of success, http: www.business.queensu.ca/kbe.

[12] Fahey, L., Prusak, L. (1988), “The Eleven Deadliest Sins Of Knowledge Management", California Management Review, Vol. 40 , No. 3

[13] Galve, C., Ortega, R. (2000). Equipos de trabajo y performance: un analisis emporico a nivel de planta productivea. Management, 3, 111-134.

[14] Grant, R. M. (1996a) "Prospering in dynamically-competitive environments: Organizational capability as knowledge integration," Organization Science (7:4), 375-387. 
[15] Grant, R. M (1996b). "Toward a knowledge-based theory of the firm," Strategic Management Journal (17:Winter), 109122 .

[16] Grant, R. M. (1997). The knowledge-based view of the firm: implications for management practice, Long Rang Planning, 30(3), 450-4.

[17] Grant, A. M. (2001). Rethinking psychological mindedness: Metacognition self-reflection and insight. Behaviour Change, 18(1), 8-17.

[18] Hendlud, G. (1994). A model of knowledge management and the N-form Corporation. Strategic Management Journal, 15, 73-90.

[19] Kirkman, B. L., Gibson, C. B., \& Shapiro, D. L. (2001). Exporting teams: enhancing the implementation and effectiveness of work teams in global affiliates. Organizational Dynamics, 30(1), 12-29.

[20] Kramer, R. (1999). Chapter8: Social uncertainty and collective paranoia in knowledge communities: Thinking and acting in the shadow of doubt.

[21] Lazear, E. P. (1998). Personnel Economics for Manager. NewYork, NY: Wiley.

[22] Leonard, D., \& Straulss, S. (1997). Putting your company's whole brain to work. Harvard Business Review, 75(4), 110121.

[23] Leonard, D., \& Sensiper, S. (1998). The role of tacit knowledge in group innovation. California Management Review, 40(3), 112-131.

[24] Miller, D., \& Shamsie, J. 1996. The resource-based view of the firm in two environments: The Hollywood film studios from 1936 to 1965. Academy of Management Journal, 39(3): 519-543.

[25] Miles, G., Miles, R. E., Perrone, V., \& Edvinsson, L. (1998). Some conceptual and research barriers to the utilization of knowledge. California Management Review, 40(3), 281-287.

[26] Nelson, R. R., \& Winter, S.G. (1982). An Evolutionary Theory of Economic Chang. Cambridge, MA: Belknap Press.

[27] Nicholls, C., Lane, H. W., \& Brechu, M. B. (1999). Taking self-managed teams to Mexico. Academy of Management Executive, 13, 15-27.

[28] Nonaka, I. (1994). A dynamic theory of organizational knowledge creation. Organizational Since, 5(1), 14-37.

[29] Nonaka, I. \& Konno, N. (1998). The concept of Ba: building a foundation for knowledge creation. California Management Review, 40(3), 40-54.

[30] Nonaka, I., Toyama, R., \& Konno, N. (2001). SECI, Ba and leadership: a unified model of dynamic knowledge creation.

[31] Nonaka, I. \& D., Teece (Eds), Managing Industrial Knowledge: Creation, Transfer and Utilization, London: Sage, pp13-43.

[32] Nonaka, I, \& H., Takeuchi. (1995). The Knowledge-Creating Company. New York: Oxford University Press.

[33] Podolny, J. M., \& Baron, J. N. (1997). Resources and relationships: Social networks and mobility in the workplace. American Sociological Review, 62, 673-693.
[34] Porter, M. E. (1985). The Competitive Advantage: Creating and Sustaining Superior Performance. NY: Free Press

[35] Roberts, J. (2000). From know-how to show-how? Questioning the role of information and communication technologies in knowledge transfer. Technology Analysis \& Strategic Management, 12(4), 429-443.

[36] Robbins, S. (2001). Organizational Behavior (9th Ed.). Upper Saddle River, NJ: Prentice-Hall.

[37] Rolland, N., Chauvel, D., (2000). Knowledge transfer in strategic alliances. In

[38] Ruggles, R. (1998). The state of the notion: knowledge management in practice. California management Review, 40(3), 80-89.

[39] Sabherwal, R., \& Becerra-Fernandez, I. (2003). An empirical study of the effect of knowledge management processes at individual, group, and organizational levels. Decision Sciences, 34(2), 225-260.

[40] Suttle, J. (Eds), Improving Life at Work: Behavioral Science Approaches to Organizational Chang, Googyear, Santa Monica, CA, 227-296.

[41] Teece, D. (1998). Capturing value from knowledge assets: the new economy, markets for know-how, and intangible assets. California Management Review, 40(3), 55-79.

[42] Thompson, L., J. Levine, \& D. Messick (Eds.), Shared cognition in organizations: The management of knowledge, Lawrence Erlbaum Assoc. Publishers, Mahwah, NJ, pp163191

[43] Uhl-Bien, M., \& Graen, G. B. (1998). Individual selfmanagement: analysis of professionals' self-managing activities in functional and cross-functional work teams. Academy of Management Journal, 41, 340-50.

[44] Von Krogh, G., Nonaka Ikujiro, Ichijo Kazuo (2000) Enabling Knowledge Creation: New Tools for Unlocking the Mysteries of Tacit Understanding Oxford: OUP

[45] Von Krogh, G. (1998). Care in knowledge creation. California Management Review, 40 (3), 133-153.

[46] Walczak, S. (2005). Organizational knowledge management structure. Journal of knowledge management, 12(4), 330-339.

[47] Wenger, E. (1999). Communities of Practice: Learning, Meaning and Identity. Cambridge, MA: Cambridge University Press.

[48] Zarraga, C., \& Bonache, J. (2003). The impact of team atmosphere on knowledge outcomes in self-managed teams. Organization Studies, 26(5).

[49] Zarraga, C., \& Garcia-Falcon, J. M. (2003). Factors favoring knowledge management in work teams. Journal of knowledge management, 7(2), 81-96.

[50] Zarraga, C., Saa-Perez, P. D. (2006). Work teams to favor knowledge management. Journal of European Business Review, 18(1), 60-76. 